\title{
Multi-Walled Carbon Nanotubes can Promote Root Hair Development Through Nitric Oxide and Ethylene Pathways
}

\section{Gan Zhao}

Nanjing Agricultural University

Yingying Zhao

Nanjing Agricultural University

Wang Lou

Nanjing Agricultural University

Dyaaaldin Abdalmegeed

Nanjing Agricultural University

Rongzhan Guan

Nanjing Agricultural University

Wenbiao Shen ( $\square$ wbshenh@njau.edu.cn )

Nanjing Agricultural University https://orcid.org/0000-0003-1525-9472

\section{Research}

Keywords: Multi-walled carbon nanotubes, Root hair, Nitric oxide, Ethylene

Posted Date: September 10th, 2020

DOl: https://doi.org/10.21203/rs.3.rs-74113/v1

License: (1) This work is licensed under a Creative Commons Attribution 4.0 International License.

Read Full License 


\section{Abstract}

Background: Although carbon nanotubes (CNTs) have the risk of polluting the ecological system, it still cannot deny its huge potential in agriculture. Studying the effects of CNTs on plant growth will help to make new assessments of the application of CNTs in agriculture.

Results: Here, we observed that the stimulation of plant root hair growth triggered by multi-walled carbon nanotube (MWCNTs) with appropriate concentrations is a universal event; however, low or excessive had no significant effect or even inhibition. Further results showed that MWCNTs could enter rapeseed root cells. Meanwhile, nitrate reductase (NR)-dependent nitric oxide (NO) and ethylene syntheses, as well as root hair formation were significantly stimulated by MWCNTs. Transcription of root hair growth related genes were also modulated. Above responses were obviously blocked by the removal of endogenous NO and ethylene with a scavenger of NO or NO/ethylene synthetic inhibitors. Similarly, MWCNTs-triggered root hair growth was obviously impaired in ein2-5 and ein3-1, two ethylene-insensitive mutants, and nia1/2, a nitric reductase defective mutant, but not in noa1 mutant, with impaired in NO-associated protein 1. Further molecular data placed NR-dependent NO synthesis linearly before ethylene production in root hair development triggered by MWCNTs.

Conclusion: Above results revealed that MWCNTs could promote root hair growth. Ethylene and NRdependent NO were required for MWCNTs-induced root hair morphogenesis via regulating genes related to root hair development, and ethylene might act downstream of NO in this process. Since root hair is one of important components for root organogenesis, above findings open a new window for the possible usage of CNTs in agriculture.

\section{Introduction}

In the past 30 years, carbon nanotubes (CNTs) have received considerable attention due to their special structures and unique physical, chemical, biological properties, and huge application potential. Many researches on CNTs have focuses on novel sources of energy, new materials, biosensors, medicine, and hydrogen storage [1-4]. Undoubtedly, the researches on CNTs-plants are also emerging $[5,6]$. However, the development of CNTs is not smooth sailing. Toxicity and environmental pollution problems have always occurred with the development of CNTs $[3,6]$. Although CNTs have the risk of polluting the ecological system, it still cannot deny its huge potential. Many scientists have used various means to reduce the toxicity of CNTs $[3,7]$. And because of vital roles of plants in the ecological system, the edible parts of crops are the possible routes for the uptake, translocation, and accumulation of CNTs, if they are used in agriculture $[5,6]$. Therefore, to promote the application of CNTs in agriculture, the interactions between CNTs and plants need to be carefully elucidated.

Previous research on the relationship between CNTs and plants mainly focused on seed germination [810], primary root growth [11-13], lateral root development [14-16], flowering [17, 18], and stress tolerance $[19,20]$. However, except the studies of Joshi et al. [21] and García-Sánchez et al. [22], few investigations 
has been finished on the functions of multi-walled carbon nanotube (MWCNTs; one of kinds of CNTs) on root hairs and corresponding mechanism, and their phenotypes were controversial. Thus, the effects of CNTs on root hairs need to be further studied.

Root hair is one of important components for root organogenesis. It could help the root system tightly integrating into the soil and increase the surface of the root system, thus helping plants successfully absorbing water and nutrients from environment [23]. Also, root hair development can help plants grow out of trouble in harmful environment [24].

During root hair development, ethylene is an important and essential signaling molecule [25-28]. ACC synthase and ACC oxidase, two critical enzymes responsible for ethylene biosynthesis, ubiquitously exist in plants [25-27]. It was further documented that ethylene not only promotes the outgrowth of the root hair, but also makes the hairless cells form root hair $[25,26]$. These conclusions were based on the enhancement of root hair development observed in the presence of ethylene [26] and 1aminocyclopropane-1-carboxylic acid (ACC), an ethylene synthetic precursor [27, 28], as well as found in ctr1 mutant (a negative regulator of ethylene signaling) [25]. Meanwhile, contrasting results were also confirmed in ein2 [26, 27], ein3 [28], and etr [29], several ethylene-insensitive mutants, and in wild-type when exogenously applied with ethylene synthetic inhibitor cobalt chloride $\left(\mathrm{CoCl}_{2}\right)[29,30]$ and aminoethoxyvinylglycine (AVG) $[25,29]$.

It is well documented that nitric oxide (NO) in plants can be produced through two routes, including enzymatic or nonenzymatic pathways. Between these, nitrate reductase (NR) and nitric oxide synthase (NOS)-like protein are two important enzymes responsible for synthesizing NO [27, 31]. Like ethylene, NO was also confirmed to be an important inducer control of root hair development [31-34]. This conclusion was based on the pharmacological and genetic evidence, showing that exogenously applied with a NOreleasing compound sodium nitroprusside (SNP) favors Arabidopsis root hair growth [31, 34], whereas the defective phenomenon was observed in nia1/2 (impaired in nitrate reductase activity) $[27,34]$ and noa 1 (encoding NO-associated protein 1; exhibiting indirectly a reduced endogenous NO level), two NOrelated mutants [31, 34], and in the wild-type when supplemented with the NO scavenger 2-(4carboxyphenyl)-4,4,5,5-tetramethylimidazoline-1-oxyl-3-oxide (c-PTIO) [31, 32], NR inhibitor tungstate, and NOS inhibitor $N^{G}$-nitro-_-arginine methyl ester hydrochloride (L-NAME) [27].

During plant development, it has been shown that both ethylene and NO can act both synergistically (in particularly) and independently [34-36]. For example, several data place ethylene synthesis linearly after NO signaling in cell wall phosphorus reutilization in P-deficient rice [35], and ethylene and NO work together to induce root hair development in Arabidopsis upon the magnesium deficiency conditions [27]. By contrast, $\mathrm{NO}$ is also required for cucumber adventitious root development elicited by ethylene [36]. Our recent pharmacological genetic evidence revealed the important role of NR-dependent NO in MWCNTstriggered plant tolerance against salinity [13]. However, no detailed evaluation has yet been carried out to assess the contribution of ethylene and NO in MWCNTs-triggered other plant responses. 
Here, by using pharmacological approach, the effects of various concentrations of MWCNTs on plant root hair growth were evaluated in rapeseed (Brassica napus. L), the third most important source of vegetable oil worldwide [37]. Our findings showed that MWCNTs could dose-dependently promote root hair development, in terms of changes in root hair density and length. The distribution of MWCNTs was also evaluated. Because both rapeseed and Arabidopsis are classified as Cruciferous plants and a high homolog exists in their genomes [38], Arabidopsis ein2-5 and ein3-1, two ethylene-insensitive mutants, and nia 1/2 and noa 1, two NO mutants, were utilized to investigate the relationship between NO and ethylene. Evidence further revealed the important key roles of both ethylene and NO in MWCNTs-triggered root hair development, and ethylene may act downstream of NR-dependent NO signaling. Above results provided a unique mechanism for NO-ethylene interaction during root hair development triggered by MWCNTs, and presented a theoretical basis for the possible application of CNTs in agriculture.

\section{Materials And Methods}

\section{Chemicals}

All chemicals were obtained from Sigma-Aldrich (St Louis, MO, USA) unless stated otherwise. The chemicals included: multi-walled carbon nanotubes (MWCNTs), 1-aminocyclopropane - 1-carboxylic acid (ACC; an ethylene synthesis precursor) [28,30], cobalt chloride $\left(\mathrm{CoCl}_{2}\right.$; an inhibitor of ACC oxidase) [29, 30], aminoethoxyvinylglycine (AVG; an inhibitor of ACC synthetase) [29,35], sodium nitroprusside (SNP; a NO-releasing compound) [31, 34], 2-(4-carboxyphenyl)-4,4,5,5-tetramethylimidazoline-1-oxyl-3-oxide (cPTIO; a specific scavenger of NO) [35, 36], tungstate (an inhibitor of nitrate reductase) [39, 40], $N^{6}$-nitro--' arginine methyl ester hydrochloride (_-NAME; a mammalian NO synthase inhibitor) [40, 41]. Additionally, the old SNP solution, produced by keeping SNP solution for at least $10 \mathrm{~d}$ in the light to eliminate the whole NO, was regarded as a negative control of SNP [40,41]. The concentrations of above chemicals were confirmed in pilot experiments, from which the maximal effects were confirmed.

The characterization of MWCNTs was carried out in our recent study [13]. They were prepared according to the methods described previously $[11,13]$. The obtained homogenate colloidal suspension was immediately used.

\section{Plant Materials and Growth Conditions}

Rapeseed (Brassica napus L. Zhongshuang 11) was purchased in Chinese Academy of Agricultural Sciences. Seeds were surface-sterilized and cultured according to previous research methods [13]. Briefly, seeds were germinated for 2 days at $25^{\circ} \mathrm{C}$ in the darkness, then the identical seedlings were cultured in the $1 / 2 \mathrm{MS}$ (pH 5.8) medium at a light intensity of $200 \mu \mathrm{mol} \mathrm{m} \mathrm{m}^{-2} \mathrm{~s}^{-1}$ and $16-\mathrm{h} / 8-\mathrm{h}\left(25 \pm 1 / 23 \pm 1{ }^{\circ} \mathrm{C}\right)$ day/night regimes, with the indicated chemicals detailed described in the Figure legends. 
Arabidopsis thaliana Columbia (Col-0) was used in this study. The wild-type (WT), noa1 and nia1/2 mutants were obtained from the Arabidopsis Biological Resource Center (http://www.arabidopsis.org/abrc). And the ein2-5, ein3-1, AUX1::AUX1-YFP, and PIN1::PIN1-GFP were generous gifts from C.W. Jin, Zhejiang University, China.

According to previous research methods [13], Arabidopsis seeds were surface-sterilized and cultured on the solid 1/2 MS medium containing $1 \%(\mathrm{w} / \mathrm{v})$ agar and $1 \%(\mathrm{w} / \mathrm{v})$ sucrose at $4{ }^{\circ} \mathrm{C}$ for 2 days, Afterwards, seeds were grown in a growth chamber at a light intensity of $100 \mu \mathrm{mol} \mathrm{m}^{-2} \mathrm{~s}^{-1}$ and $16-\mathrm{h} / 8-\mathrm{h}\left(23 / 2{ }^{\circ} \mathrm{C}\right)$ day/night regimes. Finally, five-day-old seedlings were then treated with the indicated chemicals, which were detailed described in the Figure legends.

\section{Determination of Root Hairs}

For rapeseed, root hairs were counted and root hair length was measured in the root hair zone of fifteen roots in the third millimeter segment behind the tips by using a microscope (YS100, Nikon, Tokyo, Japan) [42]. Photographs were then taken with a Nikon digital camera (P5000 COOLPIX, Nikon, Tokyo, Japan). For Arabidopsis, root hairs were detected as previous described with some modification [27], and fifteen roots were detected from the root tip to the upper $5 \mathrm{~mm}$. For rice, tomato, Chinese cabbage, wheat, radish, and Alfalfa, the calculation of root hair density and length refer to the previous method [42].

\section{Detection of MWCNTs Distribution}

Like the previous methods $[13,43]$, the distribution of MWCNTs was analyzed by transmission electron microscope. Six samples from six root tissues per treatment were investigated.

\section{Measurement of Ethylene Production, ACC oxidase and ACC Synthase Activities}

According to methods described previously [27, 34], ethylene production in roots was analyzed with a gas chromatograph (GC-7AG; Shimadzu, Tokyo, Japan).

The ACC oxidase and ACC synthase activities in root tissues were determined following the previous methods $[27,34]$.

\section{Determination of NO Content, Nitrate Reductase (NR) and NO Synthase (NOS) Activities}

According to the previous method [13,27, 34], NO in root tissues was visualized using the specific NO probe 4-amino-5-methylamino-2',7'-difluorofluorescein diacetate (DAF-FM DA), and observed by using a 
Zeiss LSM 800 confocal microscope (excitation 488 nm, emission 490-530 nm; Carl Zeiss, Oberkochen, Germany). The lower right corners of the photograph were the corresponding brightfield (BF) images. The relative fluorescence was provided as values compared to the control.

According to the previous method $[13,43]$, the NR activity in root tissues was determined spectrophotometrically at $540 \mathrm{~nm}$.

The NOS activity was analyzed using the extinction coefficient of NADPH $\left(6.22 \mathrm{mM}^{-1} \mathrm{~cm}^{-1}\right)$ [13]. Protein content was also assayed [44].

\subsection{Analysis of Gene Transcription}

RNA isolation and cDNA synthesis were carried out as previously described [13]. Real-time quantitative RT-PCR (qPCR) was conducted, and the gene-specific primers were shown as in Supplementary Material Table S1 and Table S2. Two internal control genes (rapeseed, BnActin and BnGAPDH; Arabidopsis, AtActin 2 and AtGAPDH) were used, and the gene expression levels were presented as values compared to the corresponding control samples. The quantification of the relative transcript levels was calculated using the $2^{-\triangle \Delta C T}$ method [44].

\section{Experimental Design}

In our test, all experiments were carried out in a random complete block design. Three independent experiments with at least three replicates for each were adopted, and three replicates (each replicate consisting of 15 seedling) included 45 seedlings $(15 \times 3)$ each time. At least 30 roots per treatment were used to detected NO fluorescence. To analyze the activities of ACC oxidase, ACC synthase, NR, and NOS activities, and the ethylene content, a specified weight of samples per treatment were used.

\section{Statistical Analysis}

Values are means \pm standard error (SE). Data were analyzed by one-way analysis of variance (ANOVA), taking $P<0.05$ as significant according to Duncan's multiple range test.

\section{Results And Discussion}

\section{MWCNTs-Stimulated Root Hair Growth and the Distribution of MWCNTs}

MWCNTs could affect plant growth and stress resistance. However, few studies focused on root hairs, and their conclusions are controversial [21,22]. To provide the real picture regarding the function of MWCNTs in root hair development, two-day-old rapeseed seedlings were administrated with different concentrations of MWCNTs for 3 days. Compared with the control, all concentrations of MWCNTs $(10,50$, 
100,200 , and $500 \mathrm{mg} / \mathrm{L}$ ) could differentially promote root hair development (Fig. 1a and b). Among these treatments, the response of $100 \mathrm{mg} / \mathrm{L}$ MWCNTs was maximal, and this concentration was subsequently used.

Our results matched with a previous observation, showing that MWCNTs (diameters ranging from 13 to $14 \mathrm{~nm}$ ) could significantly promote root hair growth in 70,80 , and $90 \mathrm{mg} / \mathrm{L}$ in wheat [21]. However, a controversial result was reported by García-Sánchez's study [22], revealing that $25 \mathrm{mg} / \mathrm{L} \mathrm{COOH-MWCNTs}$ (diameters ranging from 4 to $12 \mathrm{~nm}$; and the modification increases the solubility of MWCNTs) could obviously inhibit root hair growth in Arabidopsis. We further compared the parameters of different MWCNTs used in previous reports and herein (diameters ranging from 6 to $12 \mathrm{~nm}$ ), and found that the sizes of the three MWCNTs are almost the same. Therefore, it seems that different doses of MWCNTs and various plant species could be used to explain above mentioned difference.

To test our hypothesis, high concentrations of MWCNTs were applied either. As expected, the root hair development was seriously impaired by 2000 and 5000 mg/L MWCNTs, while no such significant decrease was found in the presence of $1000 \mathrm{mg} / \mathrm{L}$ MWCNTs (Supplementary Material, Fig. S1). Seven kinds of plant species, including rice, tomato, Chinese cabbage, wheat, radish, alfalfa, and Arabidopsis, were used subsequently. The results further revealed that appropriate concentrations of MWCNTs could differentially induce the growth of root hairs (Supplementary Material, Table. S3). However, lower and higher concentrations of MWCNTs normally had no such significant effect on root hairs or even inhibited their growth. Above results proved that the induction of root hairs induced by MWCNTs was a universal response.

The distribution of MWCNTs was further detected by using transmission electron microscopy. Consistent with the previous study [13], our results showed that the MWCNTs distributed in cytoplasm, intercellular space, and cell vacuole of rapeseed root tissues (Fig. 1c).

\section{Ethylene was Involved in MWCNTs-Induced Root Hair Development}

In most plants, ethylene signaling is indispensable in root hair development [25-29]. In order to assess whether ethylene participitates in MWCNTs-induced rapeseed root hair formation, we measured contents of endogenous ethylene in root tissues by using gas chromatography [27, 34]. In comparison with the control sample (Con), the time course analysis illustrated that the administration of MWCNTs for $18 \mathrm{~h}$ caused a progressive increase in the ethylene production, followed by peaking at $48 \mathrm{~h}$ and keeping a stable level until $72 \mathrm{~h}$ (Fig. 2a). Meanwhile, two critical enzymes for ethylene synthesis, 1aminocyclopropane-1 -carboxylate (ACC) synthase and ACC oxidase, were also analyzed. As expected, similar tendencies were observed in above enzymatic activities (Fig. 2b and c). Ethylene synthesis in response to MWCNTs in rapeseed is also correlated to the biological response of MWCNTs control of root hair development (Fig. 1a and b). 
To verify whether ethylene is involved in root hair development triggered by MWCNTs, two ethylene synthetic inhibitors cobalt chloride $\left(\mathrm{CoCl}_{2}\right)[29,30]$ and aminoethoxyvinylglycine (AVG) $[30,35]$ were used subsequently. Meanwhile, ACC, an ethylene synthesis precursor, was used as a positive control $[28,30]$. As expected, $10 \mu \mathrm{M} \mathrm{CoCl}_{2}$ or $3 \mu \mathrm{M}$ AVG alone, a concentration applied to individually decrease ACC oxidase $[29,30]$ and its synthetase activities [30, 35], not only impaired root hair growth (Fig. 2d and e), but also decreased ethylene content (Fig. 2f). Above results clearly confirmed the important function of endogenous ethylene in root hair development [25-28]. Further results revealed that MWCNTs control of root hair development was similar to the induction role of $3 \mu \mathrm{M} \mathrm{ACC}$. By contrast, MWCNTs-induced root hair growth was inhibited by $\mathrm{CoCl}_{2}$ or AVG. Meanwhile, $\mathrm{CoCl}_{2}$ or AVG inhibition of MWCNTs-triggered ethylene was also observed, indicating a requirement for ethylene in MWCNTs control of root hair development. It is a new finding.

Similar results were discovered in the previous studies, showing that the removal of endogenous ethylene could impair root hair growth $[25,26]$, since ethylene is an essential signal for controlling root hair development, in either nutrient-adequate conditions $[26,28]$ or nutrient-starvation surroundings $[27,34]$.

\section{NR-Dependent NO was Associated with MWCNTs-Induced Root Hair Development}

Similar to ethylene [25-28], NO is another gaseous signal molecule in root hair development [31, 32]. In order to evaluate a possible interaction between NO and MWCNTs in root hair development, the endogenous NO signal in rapeseed roots were firstly detected by 4-amino-5-methylamino-2',7'difluorofluorescein diacetate (DAF-FM DA), a membrane permeable probe used ubiquitously to monitor NO levels in plant tissues [33-35]. Figure 3a demonstrates that basal DAF-FM DA fluorescence was detected in chemical-free control samples, and that in the presence of MWCNTs, the fluorescence was significantly affected, showing the initial increase as early as $12 \mathrm{~h}$, and reaching a peak at $48 \mathrm{~h}$ after treatment (Fig. 3a and Supplementary Material Fig. S2). These results clearly suggested that MWCNTsinduced NO was an early event.

In order to illustrate the primary source(s) of NO in our experimental conditions, the two main pathways of synthesizing NO in plants, NR and NOS [27, 31, 34, 36], were assessed. NR is the most intensively studied source of NO in plants. ${ }^{47}$ However, although the plant NOS gene has not been successfully cloned, ample evidence that used the inhibitors of mammalian NOS, provided the evidence of ${ }_{L}$-argininedependent route in NO synthesis $[45,46]$. As expected, the time course experiments found that in the presence of MWCNTs, the activities of NR showed the similar tendencies, as compared to the levels of NO production (Fig. 3b). However, no significant difference was observed in NOS-like enzyme activities of rapeseed seedlings with or without MWCNTs treatments (Fig. 3c). These results matched with the previous studies [13,43], showing that endogenous NO is required for MWCNT-triggered plant tolerance against salinity stress, and further confirming that NR was the main enzymatic route for MWCNTsinduced NO, in either plant response against stress [13] or lateral root formation [43]. 
To investigate the mechanism underlying MWCNTs-elicited root hair development, NO-releasing compound SNP which was used as a positive control [34-36], NR inhibitor tungstate [40, 41], mammalian NOS inhibitor $N^{G}$-nitro-_-arginine methyl ester hydrochloride (L-NAME) [39, 40], and NO scavenger 2-(4carboxyphenyl)-4,4,5,5-tetramethylimidazoline-1-oxyl-3-oxiden potassium salt (cPTIO) [40, 47], were used in the subsequent experiments. Among these, Old SNP, containing no NO, but nitrate, nitrite, and ferrocyanide, was further regarded as a negative control of SNP $[40,41]$.

When tungstate (in particularly), or ${ }_{\text {L }}$ NAME was applied alone, both root hair growth (Fig. $3 \mathrm{~d}$ and e) and NO production (Fig. 3f) were simultaneously abolished, emphasizing the important function of endogenous NO in root hair development via NR, rather than NOS-like enzyme [48-50]. Meanwhile, we observed that an application of old SNP failed to alter root hair development as well as NO production. Subsequently, we showed that both MWCNTs- and SNP-promoted endogenous NO production and CPTIO, a NO scavenger. CPTIO alone also resulted in the decreased NO content and the significant reduction in root hair growth, further confirming the function of endogenous NO in root hair morphogenesis [31, 32]. In the presence of tungstate, MWCNT-induced NR activities were also significantly impaired (Fig. 3g), thus leading to a decreased NO production (Fig. 3f) and a reversed phenotype (Fig. 3d and e). Comparatively, since MWCNTs had no obvious effects on NOS-like activities (Fig. 3), and L-NAME could did not influence MWCNTs-induced NO (Fig. 3f) and root hair development (Fig. 3d and e). Those results thus suggested that NOS might not be the main source for NO production elicited by MWCNTs.

Combining above mentioned results, we further proved that MWCNTs-induced root hair development is dependent on NR-mediated NO synthesis.

\section{Ethylene Acts Downstream of NO in MWCNTs-Induced Root Hair Growth}

Previous Ample evidence revealed that $\mathrm{NO}$ and ethylene are key signaling molecules participating in various plant signal transduction processes. For example, both ethylene [25, 26] and NO [31-34] are individually suggested to induce root hair growth. However, the question of the relationship between ethylene and NO in MWCNTs-elicited root hair growth appears to be particularly interesting.

As shown in Figs. 2a and 3a, MWCNTs application stimulated the synthesis of NO and ethylene, and the initial inducible time points were $12 \mathrm{~h}$ and $18 \mathrm{~h}$, indicating that NO might act upstream of ethylene in MWCNTs-triggered root hair development. To confirm this hypothesis, we further investigated the effects of two ethylene synthetic inhibitors $\mathrm{CoCl}_{2}$ and AVG on the NO content; and NO scavenger CPTIO, its synthetic inhibitors tungstate and ${ }_{\mathrm{L}} \mathrm{NAME}$, on the ethylene content.

Interestingly, administration with $\mathrm{CoCl}_{2}$ and AVG, two ethylene synthetic inhibitors, did not alter NO synthesis, including its content, NR and NOS activities, under the conditions in the presence and absence of MWCNTs (Fig. 4a-d). Unlike the responses of NOS inhibitor L-NAME, both NO scavenger CPTIO and NR 
inhibitor tungstate could obviously block ethylene synthesis triggered by MWCNTs (Fig. 4e-g). However,

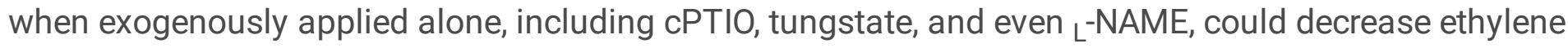
content, and inhibit ACC synthase and oxidase activities, reflecting the fact that both NR and NOS-like enzyme are responsible for NO synthesis in rapeseed seedlings under the normal growth conditions. Similar findings were reported in other plant species, including Arabidopsis [48], red kidney bean [49], and barley [50].

So, by combining data from Figs. 2-4, we concluded that some linearity may exist in NO and ethylene signalling downstream of MWCNTs. Interestingly, a similar relationship of NO and thereafter ethylene signalling was observed in the adaptive response of phosphorus-deficient rice [35]. And, the interaction relationship between NO and ethylene was found in a magnesium-deficiency condition [27]. Therefore, it could be suggested that plant response to an external stimulus is controlled by a complex array of signalling mechanisms, and plants respond differently to various environmental stimuli with the same signals, in a linear fashion or a cross-talk manner.

\section{MWCNTs-Modulated Transcripts Related to Root Hair Development were Dependent on NO and Ethylene Synthesis}

It is well documented that the TRANSPARENT TESTA GLABRA (TTG), GLABRA2 (GL2), and GLABRA3 (GL3) could accelerate the development of epidermal cells to nonhair cells, thus resulting in the inhibition in the initiation of root hair development [51,52]. The Rho-related GTPase from plants $(R O P)$ is closely associated with root hair initiation and tip growth $[53,54]$. Correspondingly, $C A P R I C E(C P C)$ and TRIPTYCHON (TRY) genes are known to trigger root hair formation [51, 52]. Auxin signals AUXINRESISTANT1 (AUX1) and PIN-FORMED1 (PIN1) participate in ethylene- and NO-elicited root hair formation via regulating corresponding marker genes related to root hair development $[34,55,56]$.

Accordingly, above molecular marker genes related to root hair growth were detected by qPCR. Like the responses of ACC and SNP, the expression of $B n A U X 1, B n P I N 1, B n C P C$, and $B n T R Y$ were up-regulated in MWCNTs-induced rapeseed root hair growth, while the expression of BnTTG and BnGL2 were downregulated (Fig. 5). Above responses could differentially blocked or impaired by the addition of $\mathrm{CoCl}_{2}, \mathrm{AVG}_{\text {, }}$ CPTIO, tungstate, indicating that both ethylene and NO are required for the modulation of these molecular marker genes in MWCNTs control of root hair development. Similarly, previous results also revealed that the genes related to root hair growth were regulated in magnesium deficiency-promoted root hair growth via ethylene and NO signals [34]. Above results indicated that MWCNTs-induced root hair growth is closely associated with the adjustment of the marker gene expression.

\section{Genetic Evidence Revealed that Ethylene and NR-Dependent NO were Associated with MWCNTs-Induced Root Hair}




\section{Development}

Pharmacological experiments may not fully reflect the true roles of endogenous ethylene and NO signals in root hair development, and may have side effects [57]. So, the genetic mutants of Arabidopsis were subsequently used. Arabidopsis is a model plant which belongs to the cruciferous family, and have high homology of rapeseed [38]. The mutants used in the experiment were NO related mutant nia 1/2 (exhibited impaired nitrate reductase activity) and noa 1 (encoding NO-associated protein 1 ; with indirectly reduced NO level in vivo), and ethylene related mutant ein2-5 (ethylene-insensitive mutant) and ein3-1 (ethylene-insensitive mutant).

Previous reports discovered that nia 1/2, noa1, ein2-5, and ein3-1 showed poor root hair growth [27, 34]. Similar results were confirmed in our study, showing lower root hair density in these four mutants, and shorter root hairs in ein2-5 and ein3-1 (Fig. 6a-C), indicating that endogenous ethylene and NO function in plant root hair growth.

For nia1/2 and noa1 mutants, under the control condition, the obvious reduction in NO and ethylene contents (Fig. 6d and f), matched with the phenotypes of the root hairs, compared to the wild-type (WT) plants (Fig. 6a-c). Biochemical analysis further showed that unlike the data in nia 1/2 mutant, although NR activity was not altered in noa 1 mutant, the similar and significant reduction in NO content was observed. While, no such significant decreases in the NO and ethylene signals were observed in ein2-5 and ein3-1 mutants. These could be explained by the fact, that both ein2-5 and ein3-1 are ethylenereceptor-related mutants that have little effect on endogenous ethylene [58-62]. Since the decreased ethylene contents were also observed in nia1/2 and noa 1 mutants (Fig. $6 \mathrm{e}$ and g), it further provides genetic evidence for the function of endogenous ethylene as a downstream signal of NO governing root hair growth.

Subsequent experiments discovered that the application of MWCNTs could induce root hair growth in wild type (WT) and noa1 mutant, reflecting the important function of NR in above response. Consistently, a significant reduction in root hair development was found in nia1/2 mutant, when challenged with MWCNTs (Fig. 6a-c). Similar phenomenon was observed in ein2-5 and ein3-1 mutants, also indicating the role of ethylene signalling.

Related ethylene and NO synthesis were also examined in above materials. As anticipated, changes in ethylene and NO contents matched with phenotypes, showing higher ethylene and NO contents in MWCNTs-treated WT, noa1, ein2-5, and ein3-1 mutants, which different from the impaired ethylene and NO contents in nia1/2 mutant (Fig. 6d and f). Thus, combined with the phenomenon in root hair development (Fig. 6a-C), above genetic evidence strongly suggested that NR-dependent NO and ethylene were required for MWCNTs-induced Arabidopsis root hair development, consistent with our previous findings in rapeseed by pharmacological, biochemical, and molecular approaches (Figs. 1-5).

The cross talk between ethylene and NO was further investigated. As shown in Fig. S3, by using tungstate, an inhibitor of NR, and AVG, an inhibitor of ACC synthetase, we observed that the removal of 
the major known sources of NO or ethylene severely impaired MWCNTs-induced ethylene production and thereafter root hair formation. These further indicated a requirement for ethylene in above MWCNTs responses. Moreover, since AVG did not affect NO production, we further confirm that ethylene acts downstream of NO signalling in MWCNTs governing root hair morphogenesis.

Auxin, a well-known phytohormone, has an important function in controlling root hair growth [31, 34]. Previous genetic evidence discovered that auxin might function downstream of ethylene and NO signaling to promote Arabidopsis root hair formation under magnesium deficiency conditions [34]. It is well documented that auxin transport is mediated by AUXINRESISTANT1 (AUX1)/LAX influx carriers and the PIN-FORMED (PIN) efflux carrier family $[53,54]$. For example, it was documented that AUX1 could increases efficiency of auxin uptake, thus resulting in the efficient transport of auxin and its accumulation within plant tissues. Here, we further evaluated the roles of auxin signaling in MWCNTs response, and found that YFP and GFP fluorescence in the roots of AUX1::AUX1-YFP and PIN1::PIN1-GFP transgenic plants were increased by MWCNTs, both of which could be differentially impaired in the presence of either tungstate or AVG (Supplementary Material, Fig. 7a and b). The changes of AtAUX1 and AtPIN1 transcripts were also confirmed by using QPCR in WT, nia1/2, and ein2-5 under normal or MWCNTstreated condition, showing the decreasing tendencies in two mutants, especially upon MWCNTs (Supplementary Material, Fig. 7c and d). These results also indicated that auxin might be controlled by ethylene and NO in MWCNTs control of Arabidopsis root hair development, which should be further assessed in the near future.

Furthermore, representative genes, including AtCPC, AtTRY, AtROP2, AtTTG1, AtGL2, and AtGL3, were analyzed [52-54]. Compared to the WT, in either the control conditions or in the presence of MWCNTs (in particularly), the down-regulated AtCPC (except in the control conditions), AtTRY and AtROP2, and the upregulated AtTTG1, AtGL2, and AtGL3 in both nia1/2 and ein2-5 mutants were observed (Supplementary Material, Fig. 8), all of which could be used to explain the defected root growth phenomena (Fig. 6a-C), since AtTRY and AtROP2 belong to root hair growth promoting factors, and AtTTG1, AtGL2, and AtGL3 are negative regulators $[51,52]$. This genetic and molecular evidence also pointed out that the molecular maker genes associated with root hair growth could be modulated by MWCNTs via NO-ethylene pathway.

Combining above results in rapeseed and Arabidopsis, we proposed that both ethylene and NO were required for MWCNTs-induced root hair morphogenesis, and ethylene might act downstream of NO in the regulatory cascade. The involvement of auxin signalling was also suggested. Related model was summarized in Fig. 9.

\section{Conclusion}

Taken together, by using pharmacology, genetics, and molecular approaches, we discovered the part of molecular mechanism underlying MWCNTs-induced root hair formation, a universal event in plants. The results revealed that ethylene and NR-dependent NO were required for MWCNTs-induced root hair 
morphogenesis via regulating genes related to root hair development, and ethylene might act downstream of $\mathrm{NO}$ in this process.

\section{Declarations}

\section{Acknowledgements}

Not applicable.

\section{Authors' Contributions}

G.Z. Y.Z. and W.S. designed and refined the research; G.Z. Y.Z. W.L. D.A. and R.G. performed research; G.Z. and Y.Z. prepared the mutant materials; G.Z. Y.Z. W.L. and W.S. analyzed data; G.Z. R.G. and W.S. wrote the article. All authors discussed the results and comments on the manuscript.

\section{Funding}

This work was partly supported by the National Key Research and Development Plan (2016YFD0101306, 2016YFD0101300) and the Postgraduate Research and Practice Innovation Program of Jiangsu Province (KYCX20_0566).

\section{Availability of data and materials}

All data generated or analyzed during this study are included in this published article.

\section{Ethics approval and consent to participate}

Not applicable.

\section{Consent for publication}

Not applicable.

\section{Competing interests}

The authors declare that they have no competing interests.

\section{References}

1. Baughman RH, Zakhidov AA, de Heer WA. Carbon nanotubes-the route toward applications. Science. 2002;297(5582):787-792.

2. Smart SK, Cassady Al, Lu G, Martin DJ. The biocompatibility of carbon nanotubes. Carbon. 2006;44(6):1034-1047. 
3. Liné C, Larue C, Flahaut E. Carbon nanotubes: impacts and behaviors in the terrestrial ecosystem-a review. Carbon. 2017;123:767-785.

4. Yin Z, Cui C, Chen H, Duoni, Yu X, Qian W. The application of carbon nanotube/graphene-based nanomaterials in wastewater treatment. Small. 2020;16(15):1902301.

5. Rico CM, Majumdar S, Duarte-Gardea M, Peralta-Videa JR, Gardea-Torresdey JL. Interaction of nanoparticles with edible plants and their possible implications in the food chain. J Agric Food Chem. 2011;59:3485-3498.

6. Ma C, White JC, Zhao J, Zhao Q, Xing B. Uptake of engineered nanoparticles by food crops: characterization, mechanisms, and implications. Annu Rev Food Sci Technol. 2018;9:129-153.

7. Guo K, Mei N. Assessment of the toxic potential of graphene family nanomaterials. J Food Drug Anal. 2014;22(1):105-115.

8. Lahiani MH, Dervishi E, Chen J, Nima Z, Gaume A, Biris AS, et al. Impact of carbon nanotube exposure to seeds of valuable crops. ACS Appl Mater Inter. 2013;5(16):7965-7963.

9. Lahiani MH, Chen J, Irin F, Puretky AA, Green MJ, Khodakovskays MV. Interaction of carbon nanohorns with plants: uptake and biological effects. Carbon. 2015;81:607-619.

10. Ali MH, Sobze JM, Pham TH, Nadeem M, Liu C, Galagedara L, et al. Carbon nanoparticles functionalized with carboxylic acid improved the germination and seedling vigor in upland boreal forest species. Nanomaterials. 2020;10(1):176.

11. Hatami M, Hadian J, Ghorbanpour M. Mechanisms underlying toxicity and stimulatory role of singlewalled carbon nanotubes in Hyoscyamus niger during drought stress simulated by polyethylene glycol. J Hazard Mater. 2017;324:306-320.

12. Kumar A, Singh A, Panigrahy M, Sahoo PK, Panigrahi KCS. Carbon nanoparticles influence photomorphogenesis and flowering time in Arabidopsis thaliana. Plant Cell Rep. 2018;37(6):901912.

13. Zhao G, Zhao Y, Lou W, Su J, We, S, Yang, X, et al. Nitrate reductase-dependent nitric oxide is crucial for multi-walled carbon nanotube induced plant tolerance against salinity. Nanoscale 2019;11(21):10511-10523.

14. Zaytseva O, Wang Z, Neumann G. Phytotoxicity of carbon nanotubes in soybean as determined by interactions with micronutrients. J Nanopart Res. 2017;19(2):29.

15. Das KK, You Y, Torres M, Barrios-Masia F, Wang X, Tao S, et al. Development and application of a digestion Raman analysis approach for studying multiwall carbon nanotube uptake in lettuce. Environ Sci-Nano 2018;5(3):659-668.

16. Fan X, Xu J, Lavoie M, Peijnenburg WJGM, Zhu Y, Lu T, et al. Multiwall carbon nanotubes modulate paraquat toxicity in Arabidopsis thaliana. Environ Pollut. 2018;233:633-641.

17. Khodakovskaya MV, Kim BS, Kim JN, Alimohammadi M, Dervishi E, Mustafa T, et al. Carbon nanotubes as plant growth regulators: effects on tomato growth, reproductive system, and soil microbial community. Small. 2013;9(1):115-123. 
18. Kumar V, Sachdev D, Paricha R, Maheshwari PH, Taneja NK. Zinc-supported multiwalled carbon nanotube nanocomposite: a synergism to micronutrient release and a smart distributor to promote the growth of onion seeds in arid conditions. ACS Appl Mater Inter. 2018;10(43):36733-36745.

19. Wang C, Liu H, Chen J, Tian Y, Shi J, Li D, et al. Carboxylated multi- walled carbon nanotubes aggravated biochemical and subcellular damages in leaves of broad bean (Vicia faba L.) seedlings under combined stress of lead and cadmium. J Hazard Mater. 2014;274:404-412.

20. Gong X, Huang D, Liu Y, Zeng G, Wang R, Xu P, et al. Roles of multiwall carbon nanotubes in phytoremediation: cadmium uptake and oxidative burst in Boehmeria nivea (L.) Gaudich. Environ Sci-Nano. 2019;6(3):851-862.

21. Joshi A, Kaur S, Dharamvir K, Nayyar H, Verma G. Multi-walled carbon nanotubes applied through seed-priming inflfluence early germination, root hair, growth, and yield of bread wheat (Triticum aestivum L.). J Sci Food Agric. 2018;98(8):3148-3160.

22. García-Sánchez S, Bernales I, Cristobal S. Early response to nanoparticles in the Arabidopsis transcriptome compromises plant defence and root-hair development through salicylic acid signaling. BMC genomics 2015;16:341.

23. Ketelaar T. The actin cytoskeleton in root hairs: all is fifine at the tip. Curr Opin Plant Biol. 2013;16(6):749-756.

24. Potters G, Pasternak TP, Guisez Y, Palme KJ, Jansen MAK. Stress-induced morphogenic responses: growing out of trouble? Trends Plant Sci. 2007;12(3):98.

25. Tanimoto M, Roberts K, Dolan L. Ethylene is a positive regulator of root hair development in Arabidopsis thaliana. Plant J. 1995;8(6):943-948.

26. Dolan L. The role of ethylene in root hair growth in Arabidopsis. J Plant Nutr Soil Sci. 2001;164(2):141-145.

27. Liu M, Liu XX, He XL, Liu LJ, Wu H, Tang CX, et al. Ethylene and nitric oxide interact to regulate the magnesium deficiency-induced root hair development in Arabidopsis. New Phytol. 2017;213(3):1242-1256.

28. Feng $Y, X u$ P, Li B, Li P, Wen X, An F, et al. Ethylene promotes root hair growth through coordinated EIN3/EIL1 and RHD6/RSL1 activity in Arabidopsis. Proc. Natl Acad Sci USA. 2017;114(52):1383413839.

29. Yang SF, Hoffman NE. Ethylene biosynthesis and its regulation in higher plants. Ann. Rev. Plant Physiol. 1984;35:155-189.

30. Prasad ME, Schofieid A, Lyzenga W, Liu H, Stone SL. C. Plant Physiol. 2010;153:1587-1596.

31. Lombardo MC, Graziano M, Polacco JC, Lamattina L. Nitric oxide functions as a positive regulator of root hair development. Plant Signal Behav. 2006;1(1):28-33.

32. Lombardo MC, Lamattina L. Nitric oxide is essential for vesicle formation and trafficking in Arabidopsis root hair growth. J Exp Bot. 2012;63(13):4875-4885. 
33. Moro CF, Gaspar M, da Silva FR, Pattathil S, Hahn MG, Salgado I, et al. S-nitrosoglutathione promotes cell wall remodeling, alters the transcriptional profile and induces root hair formation in the hairless root hair defective 6 (rhd6) mutant of Arabidopsis thaliana. New Phytol. 2017;213(4):1771-1786.

34. Liu M, Zhang H, Fang X, Zhang Y, Jin C. Auxin acts downstream of ethylene and nitric oxide to regulate magnesium deficiency-induced root hair development in Arabidopsis thaliana. Plant Cell Physiol. 2018;59(7):1452-1465.

35. Zhu XF, Zhu CQ, Wang C, Dong XY, Shen RF. Nitric oxide acts upstream of ethylene in cell wall phosphorus reutilization in phosphorus-deficient rice. J Exp Bot. 2017;68(3):753-760.

36. Xu XT, Jin X, Liao WB, Dawuda MM, Li XP, Wang M, et al. Nitric oxide is involved in ethylene-induced adventitious root development in cucumber (Cucumis sativus L.) explants. Sci. Hortic-amsterdam. 2017;215:65-71.

37. Naeem MS, Warusawitharana H, Liu H, Liu D, Ahmad R, Waraich EA, et al. 5-Aminolevulinic acid alleviates the salinity-induced changes in Brassica napus as revealed by the ultrastructural study of chloroplast. Plant Physiol Bioch. 2012;57:84-92.

38. Gale MD, Devos KM. Plant comparative genetics after 10 years, Science. 1998; 282(5389):656-659.

39. Chen WW, Yang JL, Qin C, Jin CW, Mo JH, Ye T, et al. Nitric oxide acts downstream of auxin to trigger root ferric-chelate reductase activity in response to iron deficiency in Arabidopsis. Plant Physiol. 2010;154(2):810-819.

40. Xie Y, Mao Y, Lai D, Zhang W, Zheng T, Shen W. Roles of NIA/NR/NOA1-dependent nitric oxide production and HY1 expression in the modulation of Arabidopsis salt tolerance. J Exp Bot. 2013;64(10):3045-3060.

41. Tossi V, Lamattina L, Cassia R. An increase in the concentration of abscisic acid is critical for nitric oxide-mediated plant adaptive responses to UV-B irradiation. New Phytol. 2009;181(4):871-879.

42. Guo K, Kong W, Yang Z. Carbon monoxide promotes root hair development in tomato. Plant Cell Environ. 2009;32(8):1033-1045.

43. Cao Z, Zhou H, Kong L, Li L, Wang R, Shen W. A novel mechanism underlying multiwalled carbon nanotube-triggered tomato lateral root formation: the involvement of nitric oxide. Nanoscale Res Lett. 2020;15(1):49.

44. Chen Z, Xie Y, Gu Q, Zhao G, Zhang Y, Cui W, et al. The AtrbohF-dependent regulation of ROS signaling is required for melatonin-induced salinity tolerance in Arabidopsis. Free Radical Bio Med. 2017; 108:456-477.

45. Besson-Bard A, Pugin A, Wendehenne D. New insights into nitric oxide signaling in plants, Annu Rev Plant Biol. 2008;59(1):21-39.

46. Fancy NN, Bahlmann AK, Loake GJ. Nitric oxide function in plant abiotic stress. Plant Cell Environ. 2017:40(4):462-472.

47. Lozano-Juste J, León J. Enhanced abscisic acid-mediated responses in nia 1nia2noa1-2 triple mutant impaired in nia/nr- and atnoa1-dependent nitric oxide biosynthesis in Arabidopsis. Plant Physiol. 2010;152:891-903. 
48. Bright J, Desikan R, Hancock JT, Weir LS, Neill SJ. ABA-induced NO generation and stomatal closure in Arabidopsis are dependent on $\mathrm{H}_{2} \mathrm{O}_{2}$ synthesis. Plant J. 2006;45(1):113-122.

49. Wang HH, Huang JJ, Bi YR. Nitrate reductase-dependent nitric oxide production is involved in aluminum tolerance in red kidney bean roots. Plant Sci. 2010;179(3):281-288.

50. Hu Y, You J, Liang X. Nitrate reductase-mediated nitric oxide production is involved in copper tolerance in shoots of hulless barley. Plant Cell Rep. 2015;34(3):367-379.

51. Schiefelbein J. Cell-fate specification in the epidermis: a common patterning mechanism in the root and shoot. Curr Opin Plant Biol. 2003;6(1):74-78.

52. Schiefelbein JW. Constructing a plant cell. The genetic control of root hair development. Plant Physiol. 2000;124(4):1525-1531.

53. Molendijk AJ, Bischoff F, Rajendrakumar CS, Friml J, Braun M, Gilroy S, et al. Arabidopsis thaliana Rop GTPases are localized to tips of root hairs and control polar growth. EMBO J. 2001;20(11):2779-2788.

54. Jones MA, Shen JJ, Fu Y, Li H, Yang Z, Grierson CS. The Arabidopsis Rop2 GTPase is a positive regulator of both root hair initiation and tip growth. Plant Cell. 2002;14(4):763-776.

55. Růžička K, Ljung K, Vanneste S, Podhorská R, Beeckman T, Friml J, et al. Ethylene regulates root growth through effects on auxin biosynthesis and transport-dependent auxin distribution. Plant Cell. 2007;19(7):2197-2212.

56. Jones AR, Kramer EM, Knox K, Swarup R, Bennett MJ, Lazarus CM, et al. Auxin transport through non-hair cells sustains root-hair development. Nat Cell Bio. 2009;11(1):78-84.

57. Liu W, Kong D, Gu X, Gao H, Wang J, Xia M, et al. Cytokinins can act as suppressors of nitric oxide in Arabidopsis. Proc Natl Acad Sci USA. 2013;110(4):1548-1553.

58. Binder BM, Mortimore LA, Stepanova AN, Ecker JR, Bleecker AB. Short-term growth responses to ethylene in Arabidopsis seedlings are EIN3/EIL1 independent. Plant Physiol. 2004;136(2):29212927.

59. Qiao H, Chang KN, Yazaki J, Ecker JR. Interplay between ethylene, ETP1/ETP2 F-box proteins, and degradation of EIN2 triggers ethylene responses in Arabidopsis. Genes Dev. 2009;23(4):512-521.

60. Qiao H, Shen Z, Huang SC, Schmitz RJ, Urich MA, Briggs SP, et al. Processing and subcellular trafficking of ER-tethered EIN2 control response to ethylene gas. Science. 2012;338(6105):390-394.

61. An F, Zhao Q, Ji Y, Li W, Jiang Z, Yu X, Zhang C, et al. Ethylene-induced stabilization of ETHYLENE INSENSITIVE3 and EIN3-LIKE1 is mediated by proteasomal degradation of EIN3 binding F-Box 1 and 2 that requires EIN2 in Arabidopsis. Plant Cell. 2010;22(7):2384-2401.

62. Ju C, Yoon GM, Shemansky JM, Liu DY, Ying ZI, Chang J, et al. CTR1 phosphorylates the central regulator EIN2 to control ethylene hormone signaling from the ER membrane to the nucleus in Arabidopsis. Proc Natl Acad Sci USA .2012;109(47),19486-19491.

\section{Figures}




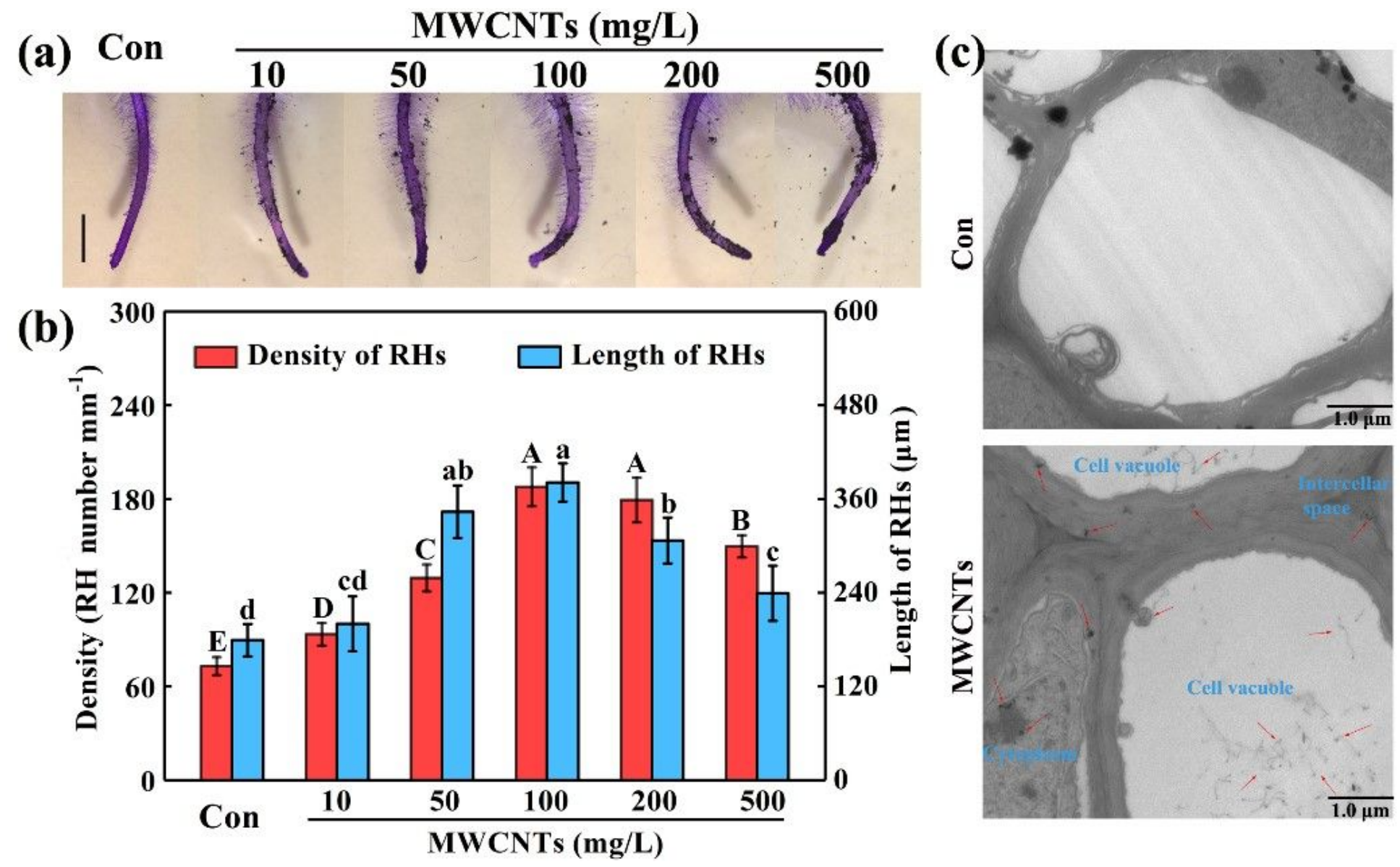

Figure 1

MWCNTs induced rapeseed root hair growth and the distribution of MWCNTs. Two-day-old seedlings were treated with the indicated concentrations of MWCNTs for 3 days. The sample without chemicals was the control (Con). Afterwards, photographs of root hairs were taken (a). Scale bar $=1 \mathrm{~mm}$. Meanwhile, the root hair $(\mathrm{RH})$ density ( $\mathrm{b}$; left) and length (right) were measured. Within each set of experiments, bars with different letters are significantly different at $\mathrm{P}<0.05$ according to Duncan's multiple range test. The distribution of MWCNTs was detected in roots in response to $100 \mathrm{mg} / \mathrm{L}$ MWCNTs (c). 
(a)

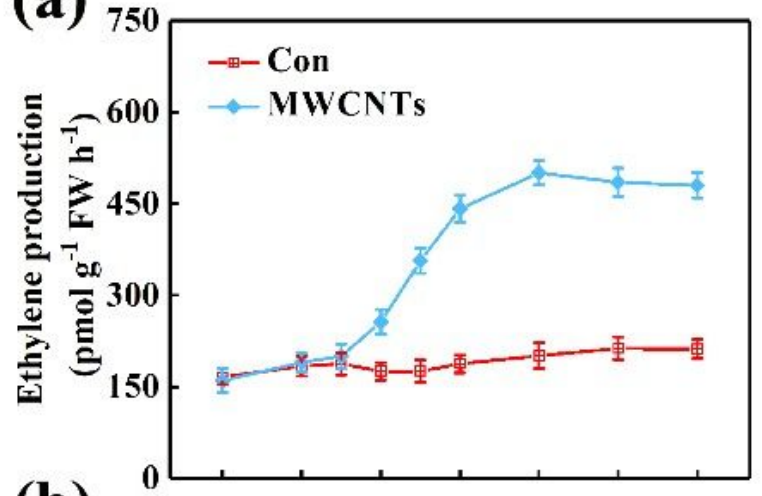

(b)

1.6

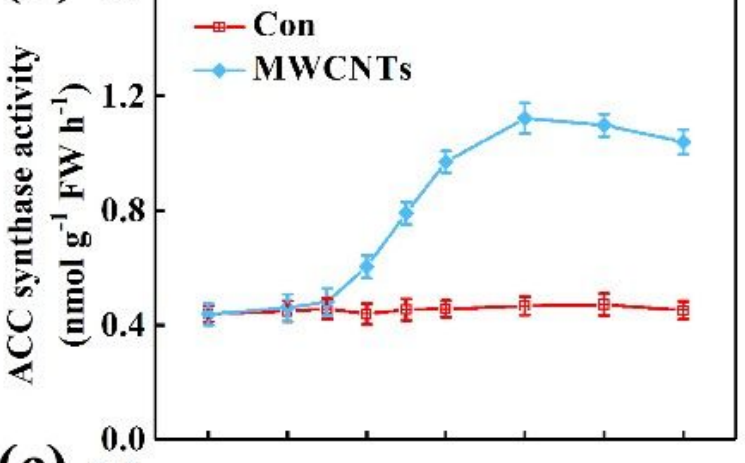

(c)

160

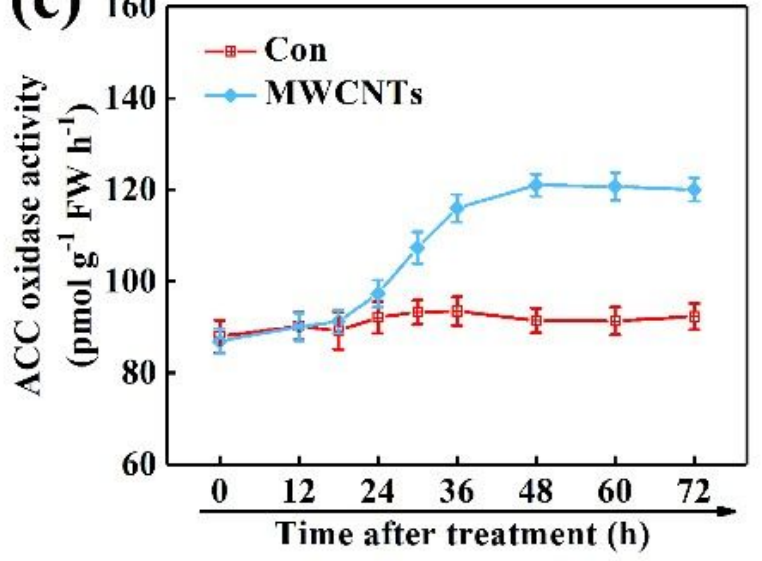

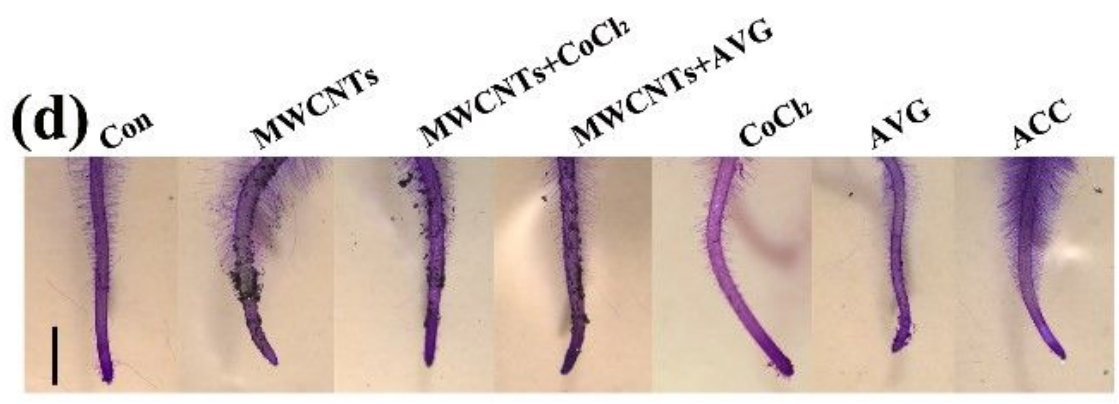

(e)

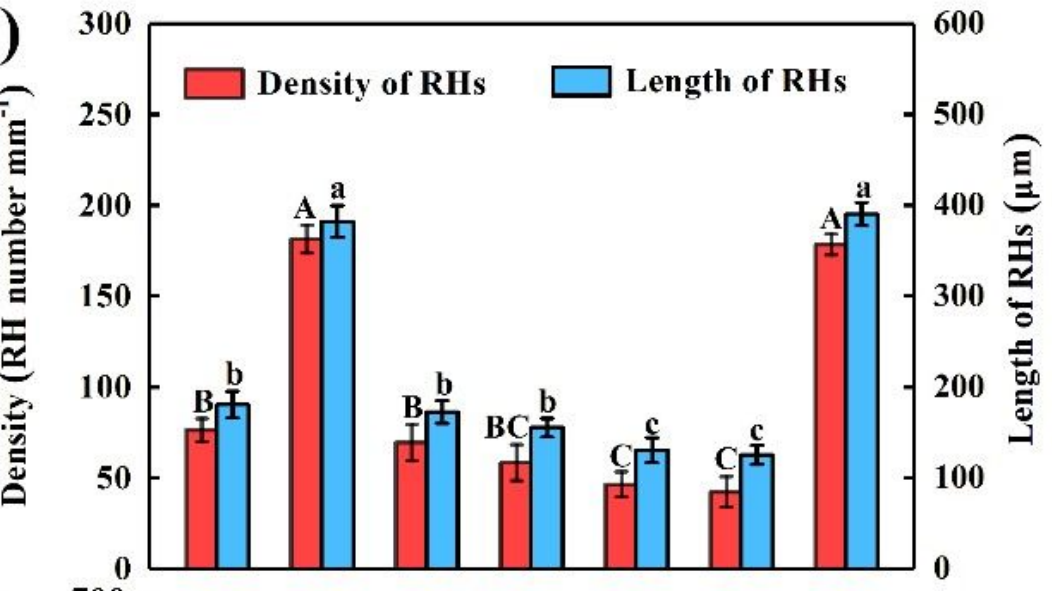

(f)
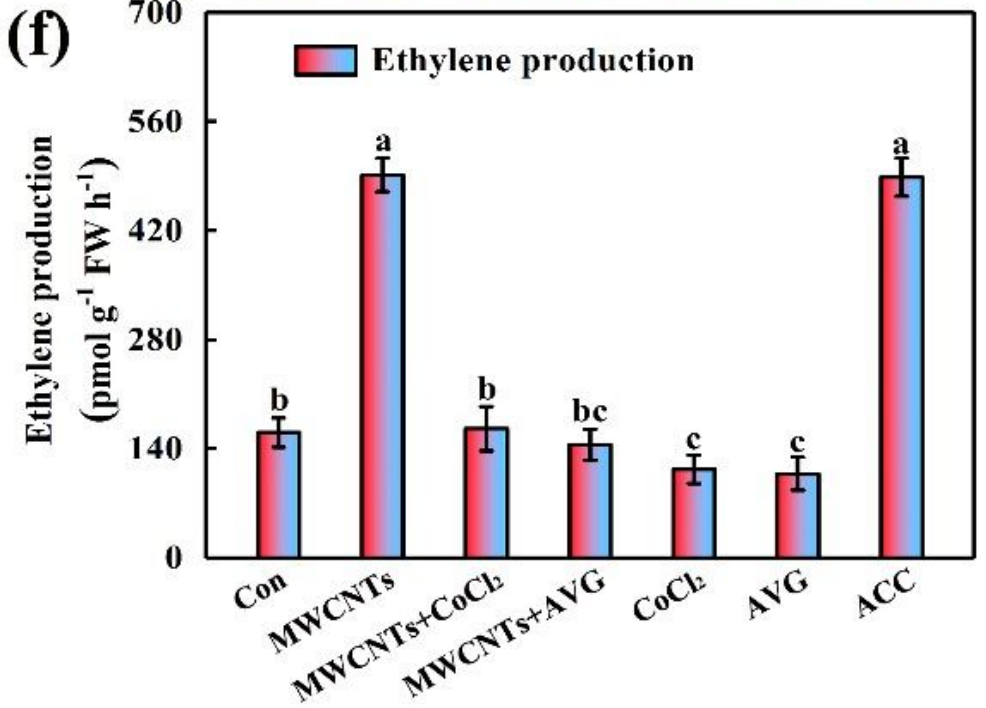

Figure 2

MWCNTs-induced ethylene production and root hair development were blocked by the removal of endogenous ethylene. Two-day-old rapeseed seedlings were treated with $100 \mathrm{mg} / \mathrm{L}$ MWCNTs, $10 \mu \mathrm{M}$ $\mathrm{CoCl} 2$, and $3 \mu \mathrm{M} \mathrm{AVG}$, alone or in combinations. The sample without chemicals was the control (Con), and $3 \mu \mathrm{M}$ ACC alone was used as a positive control. Afterwards, the time-course changes in ethylene production (a), ACC synthase (b) and ACC oxidase activities (c) were detected. After treatments for 3 days, corresponding photographs (d), the root hair $(\mathrm{RH})$ density and length (e), and ethylene production (F) were provided or determined. Scale bar $=1 \mathrm{~mm}$. Within each set of experiments, bars with different letters are significantly different at $\mathrm{P}<0.05$ according to Duncan's multiple range test. 

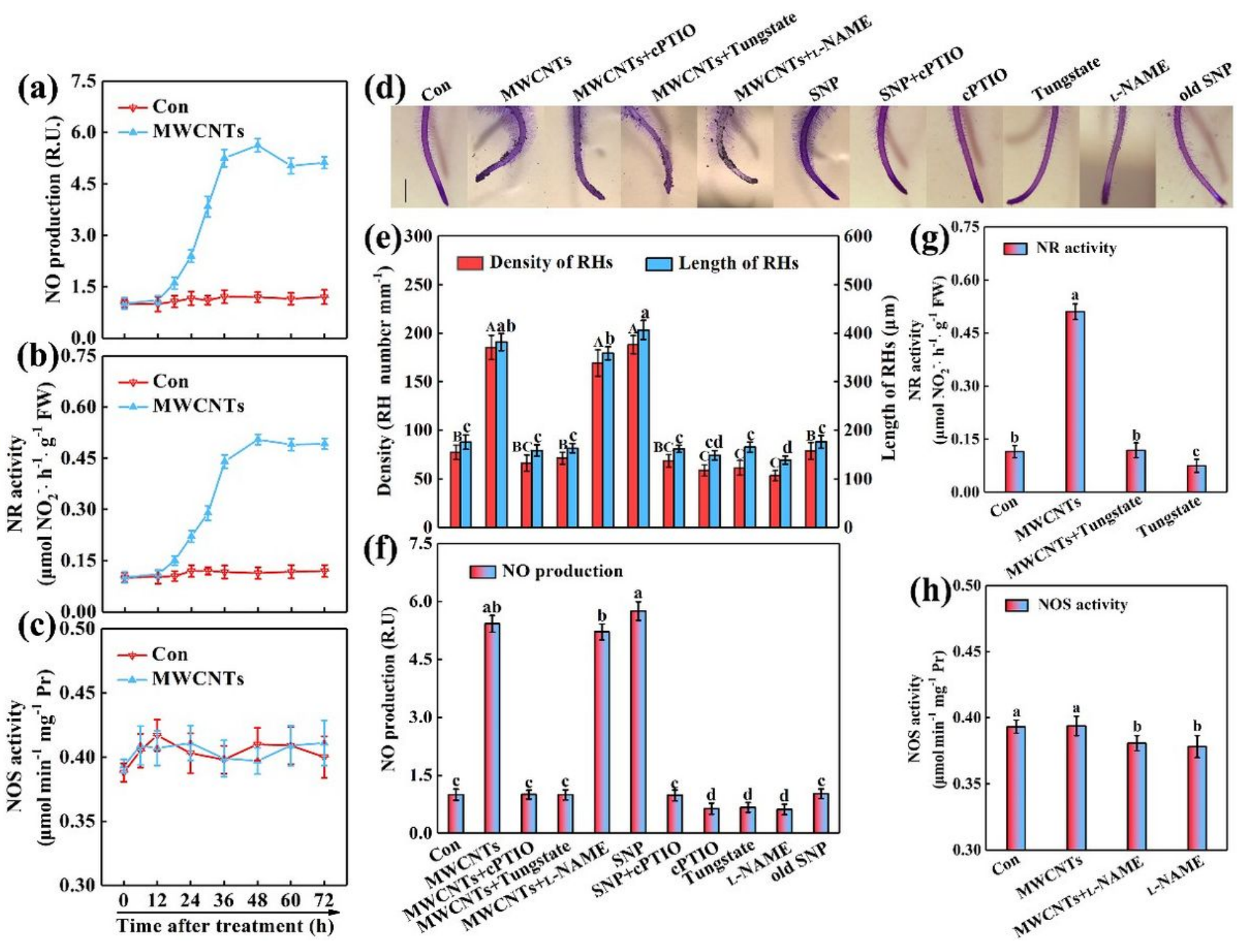

Figure 3

Nitric oxide production and root hair growth induced by MWCNTs were sensitive to CPTIO and tungstate. Two-day-old rapeseed seedlings were treated with 100 mg/L MWCNTs, $20 \mu \mathrm{M}$ SNP, $100 \mu \mathrm{M}$ cPTIO, 100 $\mu \mathrm{M}$ tungstate, and $100 \mu \mathrm{M} \mathrm{L-NAME}$, alone or their combinations. The sample without chemicals was the control (Con), and $20 \mu \mathrm{M}$ old SNP was used as the negative control of SNP. Afterwards, the time-course changes in NO production (a), NR (b) and NOS activities (c) were detected. After treatments for 3 days, corresponding photographs (d), the root hair $(\mathrm{RH})$ density and length (e), NO production (f), NR (g) and NOS activities $(\mathrm{h})$ were provided or determined. Scale bar $=1 \mathrm{~mm}$. Within each set of experiments, bars with different letters are significantly different at $\mathrm{P}<0.05$ according to Duncan's multiple range test. 
(a)

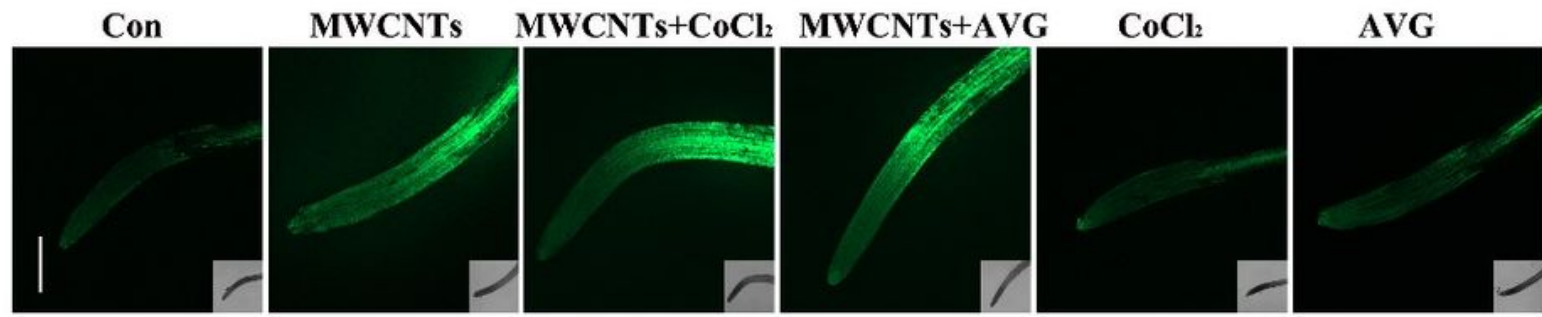

(b)
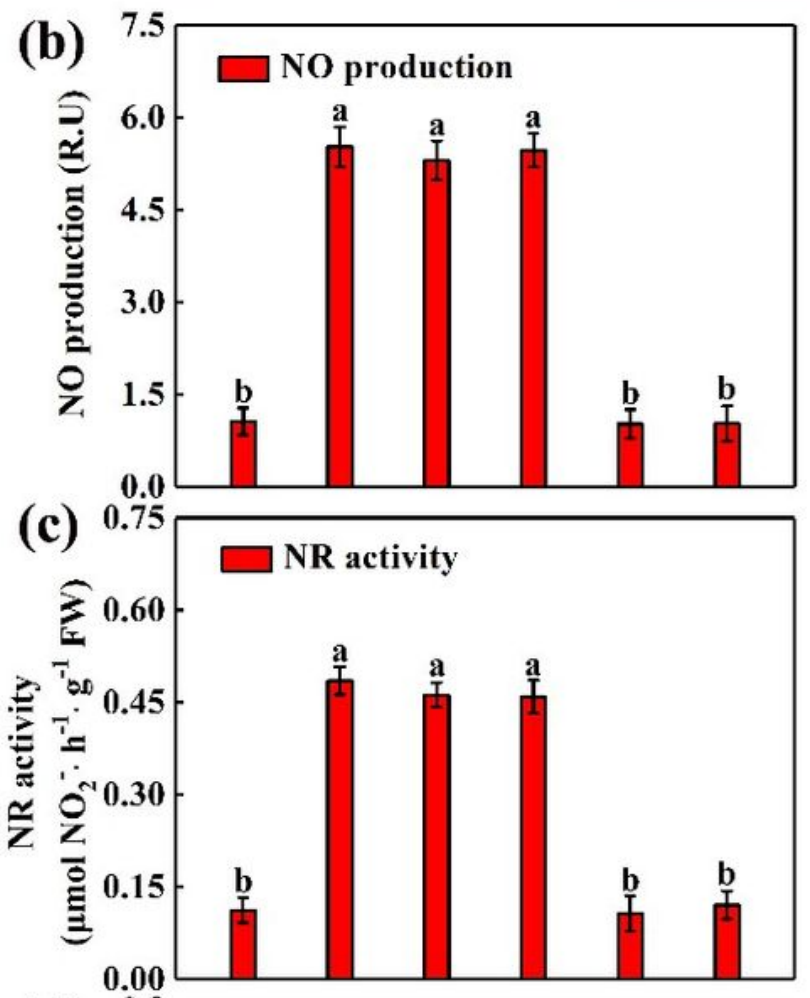

(d)

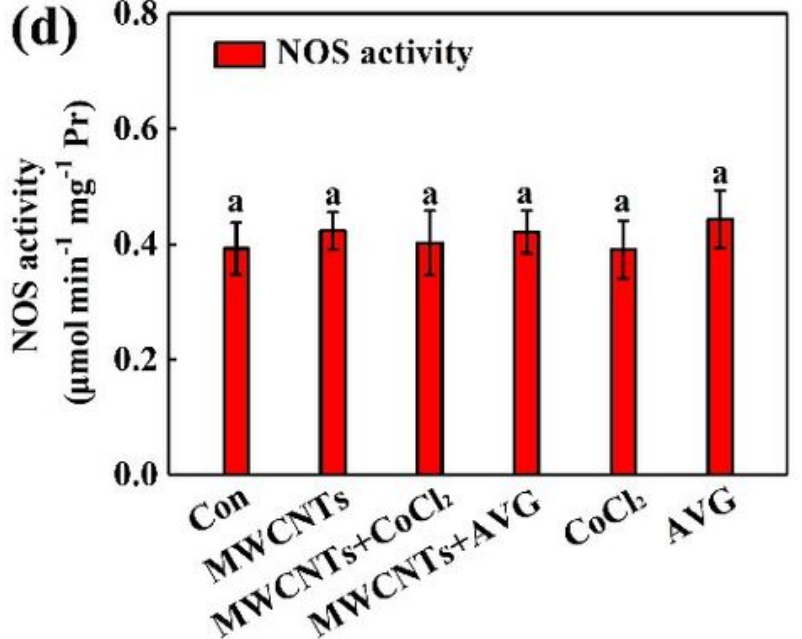

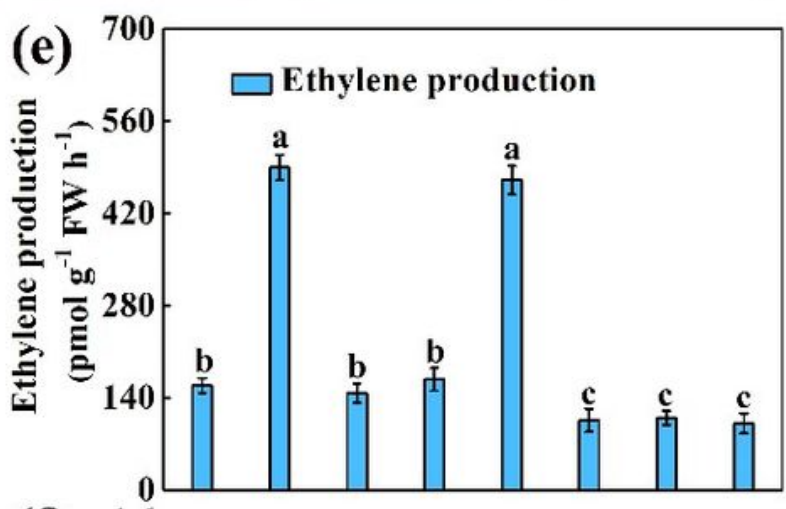

(f)

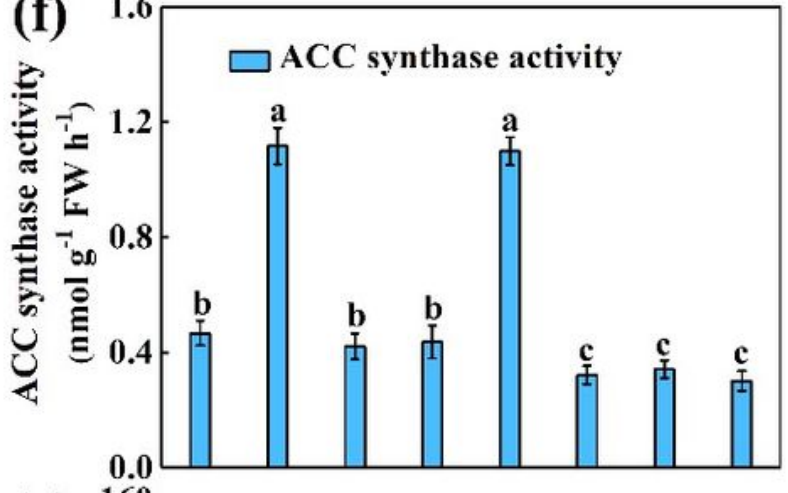

(g)

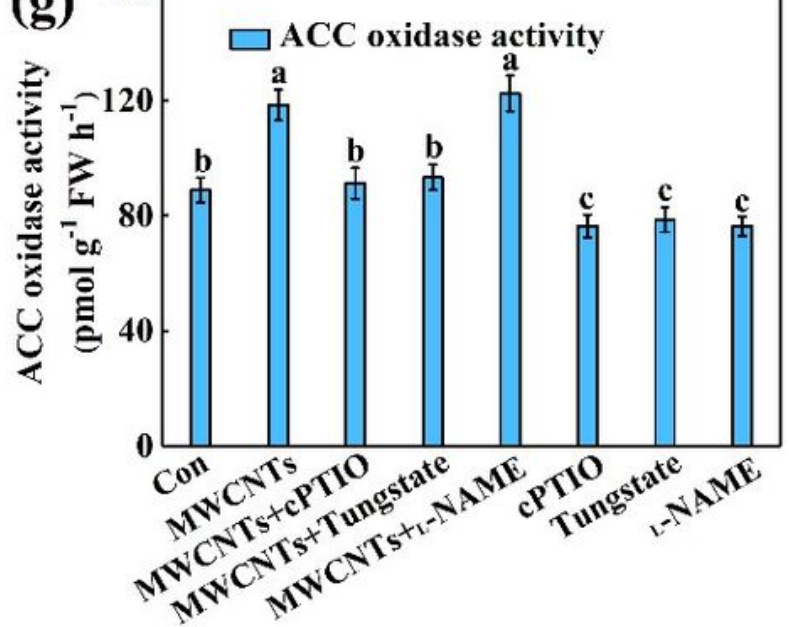

Figure 4

Crosstalk between NO and ethylene. Two-day-old rapeseed seedlings were treated with $100 \mathrm{mg} / \mathrm{L}$ MWCNTs, $10 \mu \mathrm{M} \mathrm{CoCl} 2,3 \mu \mathrm{M}$ AVG, $100 \mu \mathrm{M}$ cPTIO, $100 \mu \mathrm{M}$ tungstate, and $100 \mu \mathrm{M}$ L-NAME, alone or in combinations for $48 \mathrm{~h}$. Afterwards, endogenous NO levels (a) were determined by laser scanning confocal microscopy, and the corresponding fluorescence densities (b), NR (c) and NOS activities (d) were detected. Scale bar $=0.2 \mathrm{~mm}$. Meanwhile, ethylene production (e), ACC synthase (f) and ACC oxidase 
activities (g) were also detected. The sample without chemicals was the control (Con). Bars with different letters are significantly different at $\mathrm{P}<0.05$ according to Duncan's multiple range test.

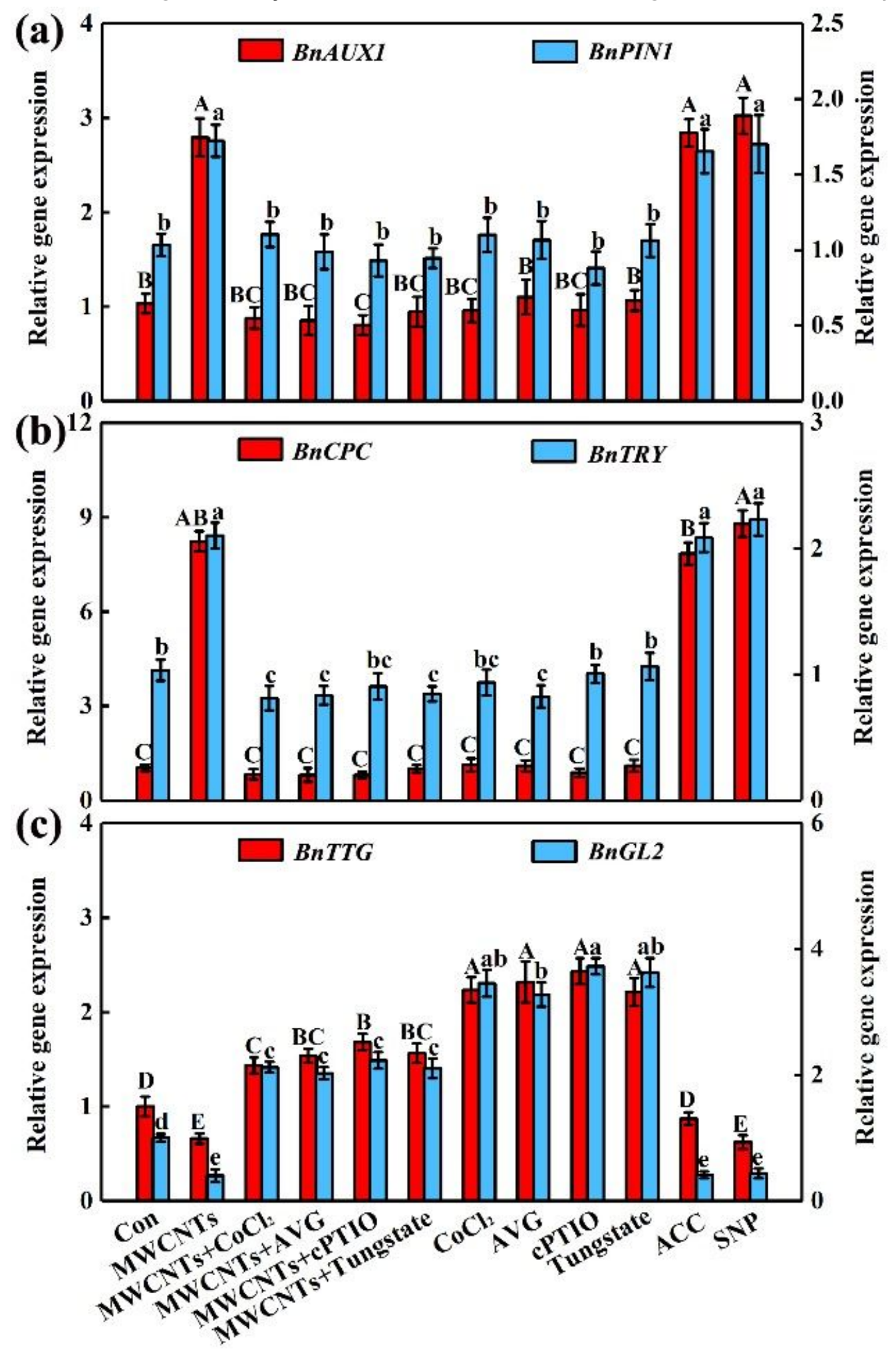

Figure 5

Transcripts of genes related to root hair development. Two-day-old rapeseed seedlings were treated with $100 \mathrm{mg} / \mathrm{L}$ MWCNTs, $10 \mu \mathrm{M} \mathrm{CoCl} 2$, and $3 \mu \mathrm{M}$ AVG, $100 \mu \mathrm{M}$ cPTIO, $100 \mu \mathrm{M}$ tungstate, $3 \mu \mathrm{M}$ ACC, and 20 $\mu \mathrm{M}$ SNP, alone or in combinations for $24 \mathrm{~h}$. Afterwards, BnAUX1 and BnPIN1 (a), BnCPC and BnTRY (b), 
and BnTTG and BnGL2 (c) transcriptional levels were analyzed by qPCR. The sample without chemicals was the control (Con). Within each set of experiments, bars with different letters are significantly different at $\mathrm{P}<0.05$ according to Duncan's multiple range test.
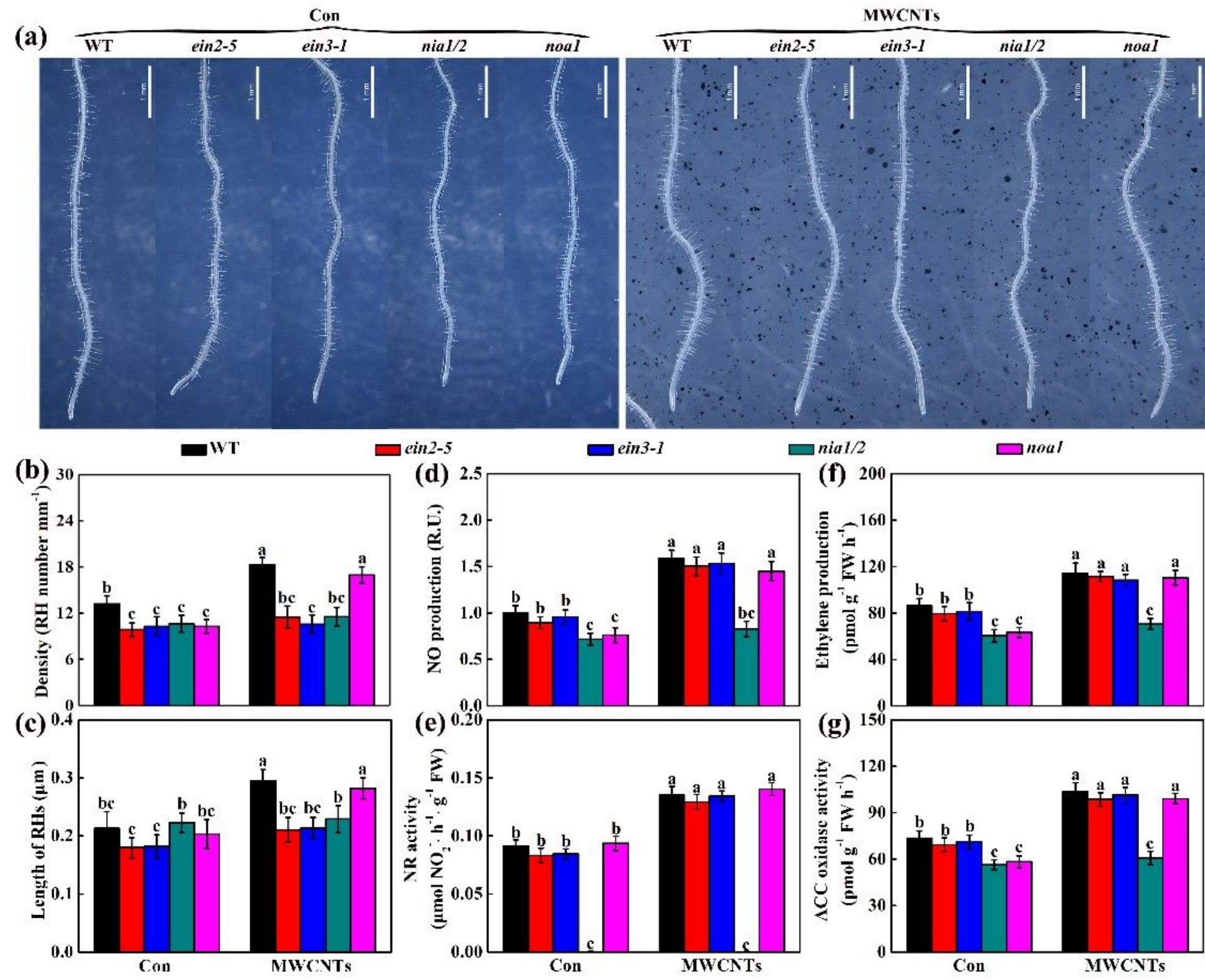

Figure 6

The involvement of $\mathrm{NO}$ and ethylene in MWCNTs-triggered root hair development in Arabidopsis. Fiveday-old wild-type (WT), ein2-5, ein3-1, nia1/2, and noa1 mutant plants were grown on MS medium for $5 \mathrm{~d}$, and then transplanted to a medium with or without $10 \mathrm{mg} / \mathrm{L}$ MWCNTs. After treatments for $5 \mathrm{~d}$, corresponding photographs (a), the root hair (RH) density (b) and length (c) were provided and determined. NO content (d), NR activity (e), ethylene content ( $f$ ), and ACC oxidase activity (g) were also detected after treatments for 3 days. Bars with different letters are significantly different at $P<0.05$ according to Duncan's multiple range test. 

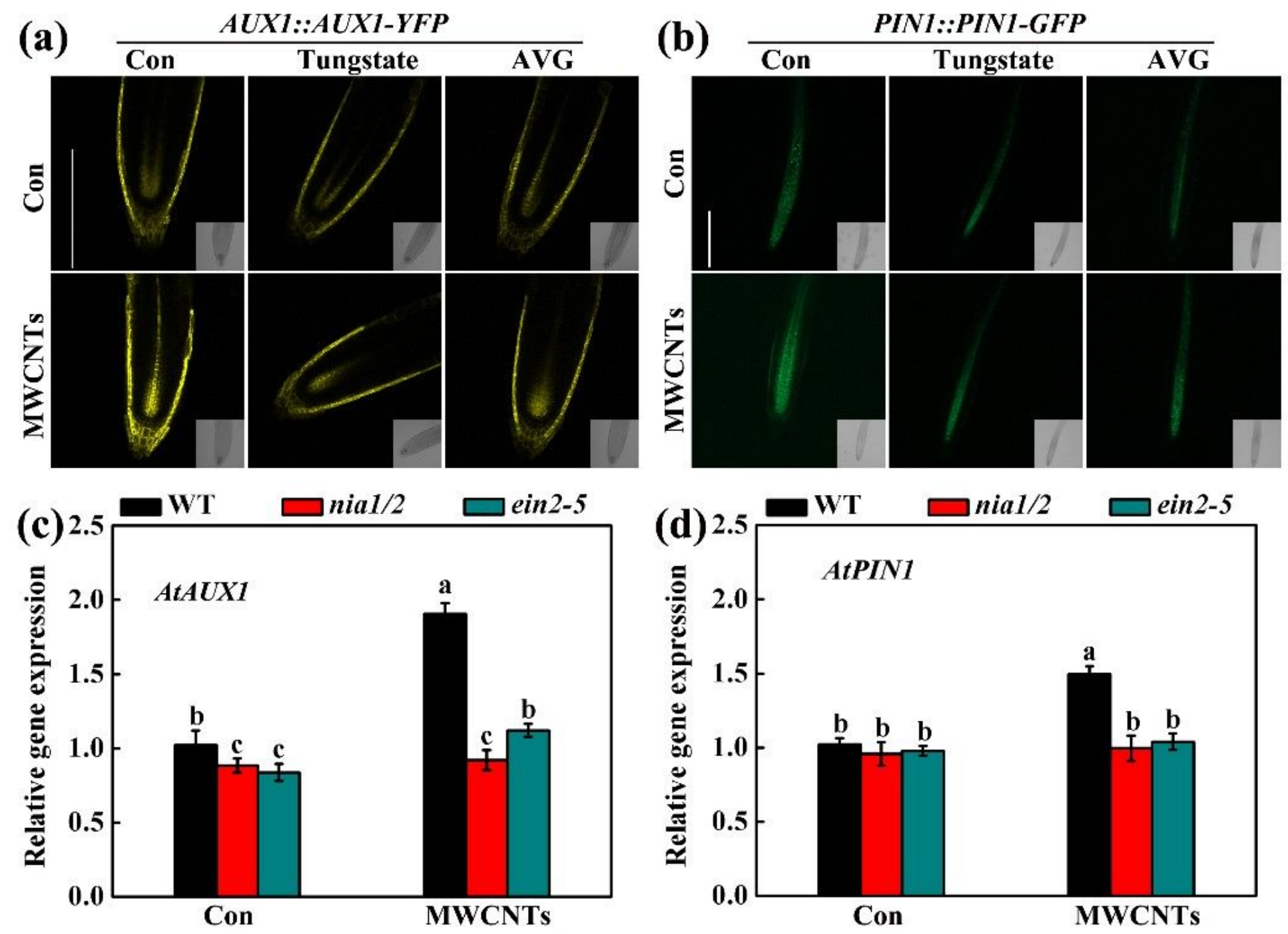

Figure 7

Changes in AUX1 and PIN. Five-day-old Arabidopsis seedlings were treated with $10 \mathrm{mg} / \mathrm{L} \mathrm{MWCNTs,} 50$ $\mu \mathrm{M}$ tungstate, and $2 \mu \mathrm{M} \mathrm{AVG}$, alone or their combinations for $24 \mathrm{~h}$. Afterwards, the YFP fluorescence images of AUX1::AUX1-YFP (a) and the GFP fluorescence images PIN1::PIN1-GFP (b) roots were detected by laser scanning confocal microscopy. Scale bar $=0.2 \mathrm{~mm}$. And the mRNA expression of AtAUX1 (c) and AtPIN1 (d) in root tissues were analyzed by qPCR. Bars with different letters are significantly different at $P$ $<0.05$ according to Duncan's multiple range test. 

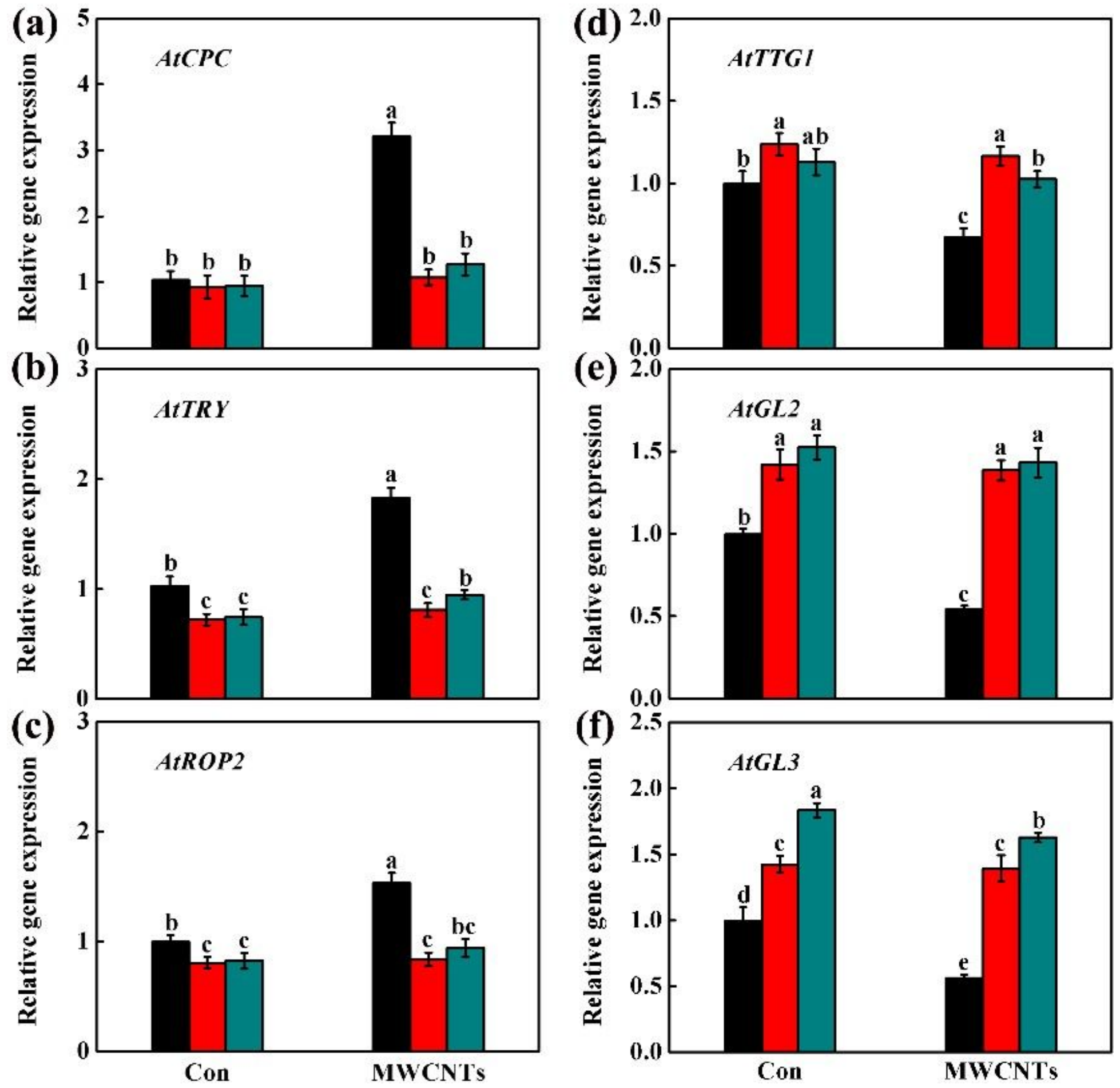

Figure 8

Changes in the transcripts of genes related to root hair formation in Arabidopsis. Five-day-old wild-type (WT), nia1/2 and ein2-5 mutants were grown on MS medium for $5 \mathrm{~d}$, and then transplanted to medium with or without $10 \mathrm{mg} / \mathrm{L}$ MWCNTs for $24 \mathrm{~h}$. Seedlings grown on MS medium without MWCNTs were the control (Con). Afterwards, the mRNA expression of AtCPC (a), AtTRY (b), AtROP2 (c), AtTTG1 (d), AtGL2 (e), and AtGL3 (f) in root tissues were analyzed by qPCR. Bars with different letters are significantly different at $\mathrm{P}<0.05$ according to Duncan's multiple range test. 


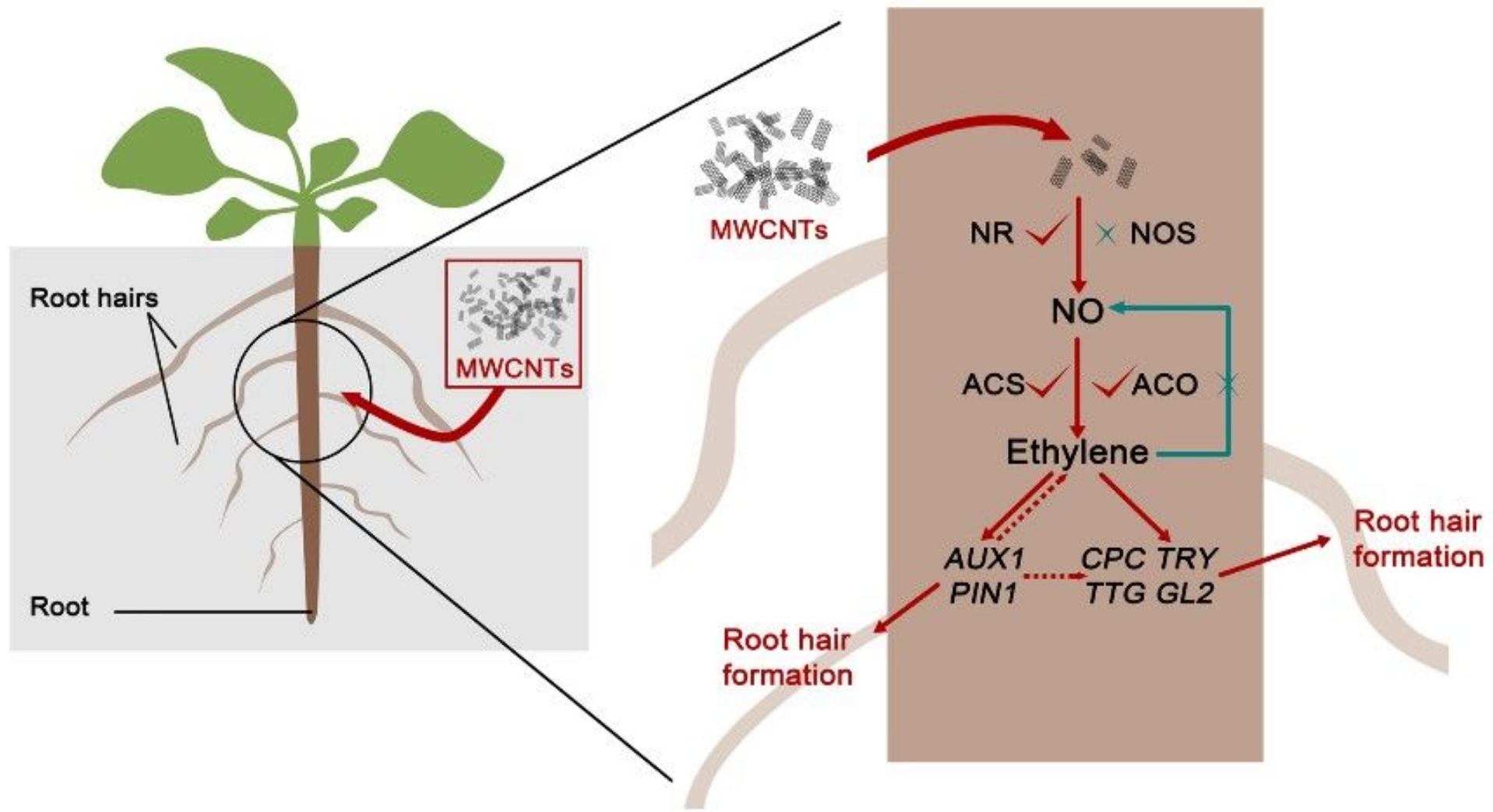

Figure 9

A model depicting the involvement of NO and ethylene in MWCNTs-induced root hair development.

\section{Supplementary Files}

This is a list of supplementary files associated with this preprint. Click to download.

- SupplementaryMaterial.docx 